\title{
Astronomical Knowledge from Holy Books
}

\author{
Sona V. Farmanyan ${ }^{1,2}$, Vardan G. Devrikyan ${ }^{1}$ and Areg M. \\ Mickaelian $^{2}$ \\ ${ }^{1}$ NAS RA, M. Abeghian Institute of Literature, Armenia \\ email: sona.farmanyan@mail.ru \\ ${ }^{2}$ NAS RA Byurakan Astrophysical Observatory (BAO), Armenia
}

\begin{abstract}
We investigate religious myths related to astronomy from different cultures in an attempt to identify common subjects and characteristics. The paper focuses on astronomy in religion. The initial review covers records from Holy books about sky related superstitious beliefs and cosmological understanding. The purpose of this study is to introduce sky related religious and national traditions (particularly based on different calendars; Solar or Lunar). We carried out a comparative study of astronomical issues contained in a number of Holy books. We come to the conclusion that the perception of celestial objects varies from culture to culture, and from religion to religion and preastronomical views had a significant impact on humankind, particularly on religious diversities. We prove that Astronomy is the basis of cultures, and that national identity and mythology and religion were formed due to the special understanding of celestial objects.
\end{abstract}

Keywords. Religion, Mythology, Religious Astronomy, Preastronomy

\section{Introduction}

The earliest visions of the Universe are mostly reflected in the holy books: Ancient Egyptian Religion (Pyramid Texts), Zoroastrianism (Avesta), Hinduism (Vedas), Buddhism (Tipitaka), Confucianism (Five Classics), Sikhism (Guru Granth Sahib), Christianity (Bible), Islam (Quran), Druidism (Mabinogion) and Maya Religion (Popol Vuh) and in the interpretations of those books. These books include various information on the creation of the Universe, Sun and Moon, the age of the Universe, Cosmic sizes, understanding about the planets, stars, Milky Way and description of the Heavens in different religions. The Holy Books can be understood either literally or contextually.

Literalism suggests:

- The holy books are the inerrant word of God

- The holy books are literally true

Contextualism suggests:

- The meaning of the text depends on its context

- Text should be examined rationally

- The holy books contain metaphors and symbols

- Religious Cosmology

\section{Religious Cosmology}

Religious Cosmology (also mythological cosmology) is a way of explaining the origin, the history and the evolution of the Cosmos or Universe based on the religious mythology 
of a specific tradition. Religious cosmologies usually include an act or process of creation by a creator deity or a larger pantheon.

In the Bible Universe of the ancient Jews was comprised of a flat disc-shaped Earth floating on water, heaven above, underworld below. Humans inhabited Earth during life and the underworld after death, and the underworld was morally neutral. In this period, the older three-level cosmology was widely replaced by the Greek concept of a spherical Earth suspended in Space at the centre of a number of concentric heavens. We can encounter this three-level structured Universe also in ancient Armenian Cosmology. The early Armenians understanding of the structure of the Universe is preserved in the ancient "Vahagns Birth folk-song, recorded by the 5th century historian Moses of Khoren. According to this song the Universe has tripartite structure: Sky-Earth-Sea. The Earth's creation, according to Mormon scripture, was not ex nihilo, but organized from existing matter. The faith teaches that this Earth is just one of many inhabited worlds, including a planet or star Kolob which is said to be nearest the throne of God. In Tipitaka, the Universe comes into existence dependent upon the actions of its inhabitants. Buddhists posit neither an ultimate beginning nor final end to the Universe, but see the Universe as something in flux, passing in and out of existence, parallel to an infinite number of other Universes doing the same thing. Quran teaches that God created the Universe, including Earth's physical environment and human beings (M. Iqbal 2007). The highest goal is to visualize the Cosmos as a book of symbols for meditation and contemplation for spiritual upliftment or as a prison from which the human soul must escape to attain true freedom in the spiritual journey to God. In Hindu cosmology it is believed that everything takes its birth in the Universe (Mitcham 2005). And the Universe is considered to constantly expand since creation and disappear into a thin haze after billions of years. Jain texts describe the shape of the Universe as similar to a man standing with legs apart and arm resting on his waist. This Universe, according to Jainism, is broad at the top, narrow at the middle and once again becomes broad at the bottom (Soni 1998).

\section{Discussion}

As Nobel Prize Winner Freeman Dyson said: "Science and religion are two windows that people look through, trying to understand the big Universe outside, trying to understand why we are here." Thus, Science and Religion are complementary. Both science and religion are not unchanging, timeless, or static because both are complex social and cultural endeavours that have changed through time across languages and cultures (Stenmark 2004). By discussing religious cosmologies, we come to the conclusion that Astronomy recognizes reason, observation, and proof, while religions incorporate disclosure, confidence and consecration whilst additionally recognizing Philosophical and Metaphysical clarifications with respect to the investigation of the Universe. We can claim that Astronomy is the basis of cultures, and that national identity and mythology and religion were formed due to the special understanding of celestial objects.

\section{References}

Mitcham, Carl 2005, Encyclopedia of Science, Technology, and Ethics, Macmillan Reference USA. p. 917

Muzaffar, Iqbal 2007, Science 83 Islam, Greenwood Press

Soni, Jayandra; Craig, E. (Eds.) 1998, "Jain Philosophy". Routledge Encyclopedia of Philosophy, London: Routledge

Stenmark, Mikael 2004, How to Relate Science and Religion: A Multidimensional Model, Grand Rapids, Mich.: W.B. Eerdmans Pub. Co. 